\title{
Erratum to: Regulatory Toxicological Studies: Identifying Drug-Induced Liver Injury Using Nonclinical Studies
}

\section{Elizabeth Hausner and Imran Khan}

\section{Erratum to:}

Chapter 19 in: Minjun Chen and Yvonne Will (eds.), Drug-Induced

Liver Toxicity, Methods in Pharmacology and Toxicology, https://doi.org/10.1007/978-1-4939-7677-5_19

The original version of Chapter 19 was inadvertently published with incorrect author name sequence as "Imran Khan and Elizabeth Hausner" instead of "Elizabeth Hausner and Imran Khan". The chapter has been updated. 